\title{
Локализация корреляций в излучении многоволнового лазера со случайной распределенной обратной связью
}

\author{
И.Д. Ватник ${ }^{1,2}$, О.А. Горбунов ${ }^{1,2, *}$, Ш. Сугаванам ${ }^{3}$, Д.В. Чуркин ${ }^{2}$ \\ ${ }^{1}$ Институт автоматики и электрометрии СО РАН \\ ${ }^{2}$ Новосибирский государственный университет \\ ${ }^{3}$ Aston University of Photonics Technologies \\ *E-mail: gorbunov86oleg@gmail.com
}

DOI:10.31868/RFL2018.72-73

Изучение спектральных корреляций, определяющих статистические свойства излучения волоконных лазеров, представляет значительный интерес. Наименее изученными в этом отношении являются волоконные лазеры со случайной распределенной обратной связью (СРОС). На настоящий момент известно, что излучение в лазерах такого типа является коррелированным, различные спектральные компоненты в спектре излучения статистически зависимы [1]. В указанной работе вывод о наличии корреляций делался на основании изучения функции распределения вероятности интенсивности.

В настоящей работе было произведено прямое одновременное измерение временной динамики интенсивности двух спектральных линий волоконного лазера со СРОС. Были обнаружены слабые корреляции как для близко расположенных линий спектра, так и для удаленных. Измерение времени распространения волн по волокну позволило локализовать область внутри лазера, внутри которой происходило формирование корреляций.

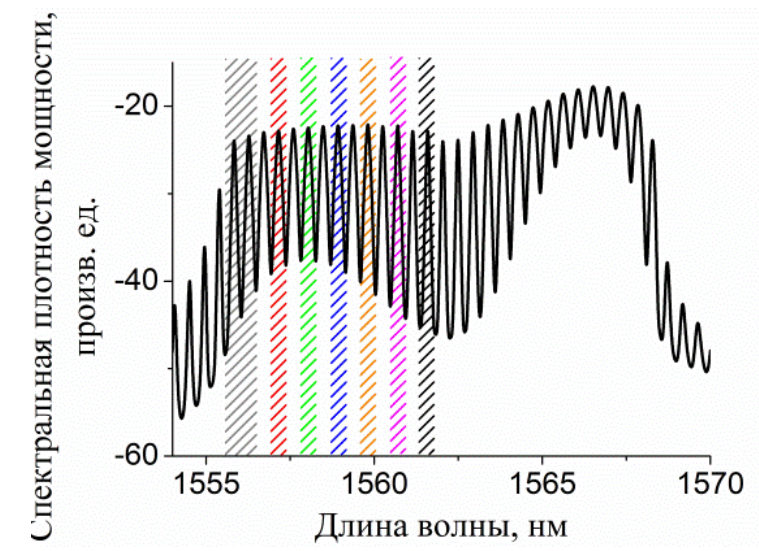

Рис. 1. Положения изучаемых линий в спектре генерации.

Измерения проводились на волоконном лазере со СРОС с фильтром Лио [2], спектр которого состоял из отдельных линий шириной около 0,5 нм (определяемой спектральной шириной фильтра Лио). Излучение на выходе лазера делилось ответвителем на две части, каждая из которых пропускалась через спектральный фильтр, вырезающий интересующую часть спектра. Полученные спектральные линии регистрировались двумя быстродействующими фотодетекторами, передававшими сигнал на два канала цифрового осциллографа с полосой 16 ГГц. На рис. 1 на спектр генерации наложены положения спектральных фильтров: первый регистрировал две линии на краю спектра, положение второго поочередно настраивалось на другие линии. 


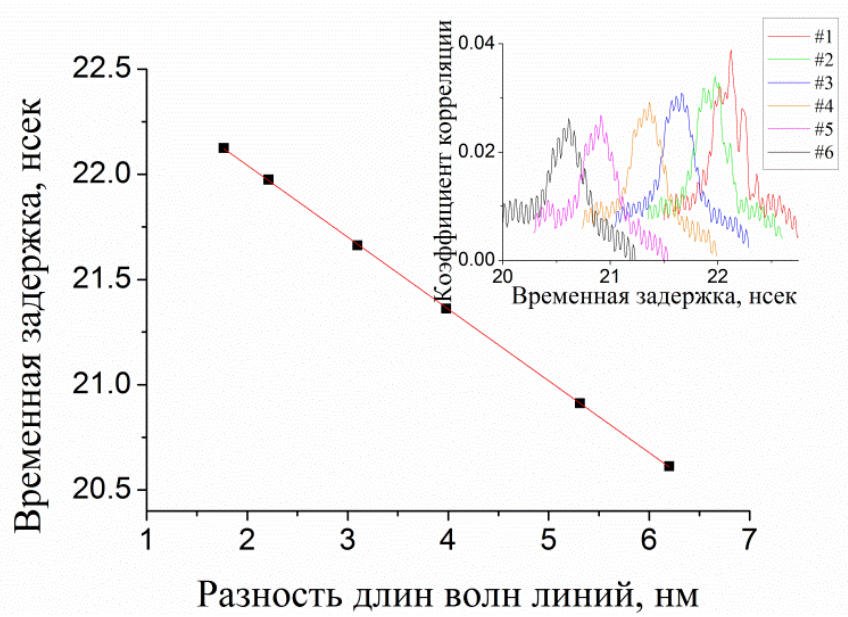

Рис. 2. Зависимость временной задержки от номера линии и аппроксимация ее прямой. На вставке - зависимость ЛКК от временной задержки между измеряемыми динамиками интенсивности для всех пар линий, цвета соответствуют рис. 1 .

Для каждой пары одновременно измеренных временных динамик был рассчитан линейный коэффициент корреляции (ЛКК). Величина ЛКК оказалось малой, - около 0,04 для соседних спектральных линий, и убывающей с ростом спектрального интервала между ними. Малая величина корреляции может быть объяснена большой шириной исследуемых линий.

Интерес представляет также зависимость временной задержки сигналов относительно друг друга. Вставка на рис. 2 показывает ЛКК как функцию задержки между каналами для всех пар линий. Видно, что максимумы этих функций находятся в различных точках: две волны, возникшие в результате нелинейного взаимодействия одновременно в некоторой точке волокна, достигнут осциллографа за разное время за счет дисперсии групповых скоростей. Аналитический вид этой зависимости $\tau\left(\lambda_{i}\right) \simeq t_{0}-L D\left(\lambda_{i}-\lambda_{0}\right)$,где $\tau$ - задержка между моментами регистрации линий с длинами волн $\lambda_{i}$ и $\lambda_{0}$ в двух каналах, $L-$ расстояние, проходимое волнами между возникновением и регистрацией, $t_{0}-$ временная задержка между каналами за счет всех факторов кроме дисперсии, $D$ коэффициент дисперсии волокна. На рис. 2 показана зависимость величины задержки от спектрального интервала между изучаемыми линиями.

Зная коэффициент дисперсии, можно по наклону аппроксимирующей прямой вычислить характерную длину возникновения корреляций $L$. Она равняется 11 км, что можно интерпретировать как некоторое среднее расстояние от конца волокна, на котором возникают корреляции. Возможна также оценка интервала, в котором они возникают: для этого нужно учесть конечную ширину пиков на рис. 2, и построить аппроксимирующие прямые в полученных пределах. Результат дает разброс по $L$ от 15 до 28 км.

Авторы выражают благодарность С.И. Каблукову, чью идеи стали отправной точкой для работы.

Работа выполнена при поддержке проекта РФФИ 16-32-60184.

\section{Литература}

[1] O.A. Gorbunov, S. Sugavanam, D.V. Churkin, Opt. Lett. 40, 1783 (2015).

[2] S. Sugavanam, Z. Yan et al, Opt. Express 22 (3), 2839 (2014). 